\title{
An Element in the $\alpha 1$-Tubulin Promoter Is Necessary for Retinal Expression during Optic Nerve Regeneration But Not after Eye Injury in the Adult Zebrafish
}

\author{
Marie-Claude Senut, Abhilasha Gulati-Leekha, and Daniel Goldman \\ University of Michigan, Mental Health Research Institute, Department of Biological Chemistry, Ann Arbor, Michigan 48109-0720
}

\begin{abstract}
We have shown previously that a $1.696 \mathrm{~kb}$ upstream fragment of the goldfish $\alpha 1$-tubulin promoter was capable of driving green fluorescent protein (GFP) expression in the developing and regenerating zebrafish CNS in a pattern closely mimicking the endogenous $\alpha 1$ tubulin gene. Comparison of fish and rat $\alpha 1$-tubulin promoters identified a $64 \mathrm{bp}$ region with a conserved repetitive homeodomain (HD) consensus sequence core (TAAT) and a nearby basic helix-loop-helix binding E-box sequence (CANNTG), which led us to speculate that it could be of importance for regulating $\alpha 1$-tubulin gene transcription. To address this issue, we examined the ability of deletion mutants of the $1.696 \mathrm{~kb}$ promoter to drive expression of GFP in zebrafish retinal cells under normal conditions and after injury. Interestingly, although wild-type $1.696 \mathrm{~kb}$ and mutant promoters, lacking the E-box and/or HD sequences, exhibited rather similar patterns of GFP expression in the developing retina, significant differences were noticed in the mature retina. First, although the $1.696 \mathrm{~kb}$ promoter directed transgene expression to retinal neurons and progenitor cells, the activity of mutant promoters was drastically reduced. Second, we found that the E-box and HD sequences were necessary for transgene reinduction during optic nerve regeneration, but were not as important for transgene expression in regenerating retinal neurons after eye injury. In this latter lesion model, remarkably, both $1.696 \mathrm{~kb}$ and mutant promoters targeted GFP expression to Müller glia-like cells, some of which re-entered the cell cycle. These new findings will be useful for identifying the molecular signals necessary for successful CNS regeneration.
\end{abstract}

Key words: tubulin; gene expression; homeodomain; E-box; regeneration; retina; visual system; zebrafish

\section{Introduction}

Neurite outgrowth and elongation are key prerequisites for the development and regeneration of the vertebrate nervous system and rely on parameters both extrinsic and intrinsic to the injured neuron/axon (Horner and Gage, 2000). Successful regeneration is associated with the expression of regeneration-associated genes (RAGs) that are selectively upregulated during axonal growth and progressively silenced as the axon reaches its target (Skene, 1989; Plunet et al., 2002). RAGs include cytoskeletal proteins (Plunet et al., 2002) such as $\alpha$ - and $\beta$-tubulin that are essential for mediating axonal growth (Baas, 1997; Suter and Forscher, 2000). Of all the $\alpha$-tubulin isoforms identified in rodents (Gozes and Littauer, 1978; Villasante et al., 1986; Stanchi et al., 2000), only the $\alpha 1$ isoform is abundant in the CNS and is neuron-specific (Lewis et al., 1985; Miller et al., 1987). $\alpha 1$-tubulin mRNA expres-

\footnotetext{
Received Jan. 21, 2004; revised July 12, 2004; accepted July 14, 2004

This work was supported by National Institutes of Health (NIH) Training Grant MHi15794-24, a grant from the Wilson Medical Research Foundation, and Grant MEDC 38 from the Michigan Economic Development Corporation, Life Sciences Corridor. The Zebrafish International Resource Center is supported by Grant RR12546 from NIHNational Center for Research Resources. We thank Rebecca Bernardos for initial examination of our EHD transgenic fish, Prof. Pamela Raymond and Dr. Steven Suhr for enlightening discussions, and all the members of the Goldman laboratory for their help and support.

Correspondence should be addressed to Daniel Goldman, University of Michigan, Mental Health Research Institute, Department of Biological Chemistry, 205 Zina Pitcher Place, Ann Arbor, MI 48109-0720. E-mail: neuroman@umich.edu.

D0I:10.1523/JNEUROSCI.2281-04.2004

Copyright $\odot 2004$ Society for Neuroscience $\quad$ 0270-6474/04/247663-11\$15.00/0
}

sion correlates with the growth of both developing and regenerating neurons (Lewis et al., 1985; Miller et al., 1987, 1989; Tetzlaff et al., 1991; Ma et al., 1992; Mathew and Miller, 1990, 1993; Fournier and McKerracher, 1997; Lorenzo et al., 2002).

The promoter regions and transcription factors that regulate $\alpha 1$-tubulin expression in the regenerating CNS are mostly unknown. Their identification is not only important for understanding the mechanisms underlying CNS regeneration, but is also crucial to the design of future therapeutic strategies for brain repair. Analysis of transgenic mice expressing a LacZ reporter gene under the control of the rat $\alpha 1$-tubulin promoter demonstrated that a $1.1 \mathrm{~kb}$ upstream sequence are sufficient for directing transgene expression in developing and axotomized motor and sympathetic neurons (Gloster et al., 1994; Bamji and Miller, 1996; Wu et al., 1997). The $\alpha 1$-tubulin promoter starts expressing as soon as neurons are born (Gloster et al. 1999) and has subsequently been used for neural progenitor identification and isolation (Roy et al., 2000); its activation via the C/EBP family of transcription factors was recently shown to contribute to the passage from progenitor to neuronal cell phenotype (Menard et al., 2002). Although transgenic mice have contributed significantly to our understanding of $\alpha 1$-tubulin promoter activity, fish models offer several unique advantages (Udvadia and Linney, 2003). Specifically, unlike mammals, the fish CNS displays remarkable regenerative potential in response to injury, which makes it a valuable model for studying successful CNS regeneration in the 
adult (Bernhardt, 1999). Furthermore, $\alpha$-tubulin is also reexpressed in the regenerating fish CNS after injury (Burrell et al., 1978; Hieber et al., 1992; Bormann et al., 1998).

We previously showed that transgenic zebrafish expressing a green fluorescent protein (GFP) reporter gene under the control of a $1.696 \mathrm{~kb}$ upstream fragment of the goldfish $\alpha 1$-tubulin promoter along with its first intron $(-1696 \alpha 1$ TIpEGFP) exhibited a pattern of GFP expression similar to that described for the endogenous $\alpha 1$-tubulin gene (Hieber et al., 1998; Goldman and Ding, 2000; Goldman et al., 2001). After optic nerve crush, a dramatic increase in GFP expression is observed in the axotomized retinal ganglion cells (RGCs) (Goldman et al., 2001). Comparison of fish and rat $\alpha 1$-tubulin promoters identified a conserved region, which contains a repetitive homeodomain (HD) consensus sequence core (TAAT) with a flanking basic helix-loop-helix binding E-box sequence (CANNTG) (Hieber et al., 1998). Using a deletion strategy, we show in the present study that although these elements are not essential for $\alpha 1$-tubulin gene transcription to occur in the zebrafish RGCs during development or in the regenerating retina after neuronal damage, they are, however, necessary for re-inducing gene transcription in the axotomized RGCs in response to optic nerve crush.

\section{Materials and Methods \\ Animals}

Danio rerio embryos and adult fish were used in this study. They were obtained from our breeding colony and raised with a 14:10 light/dark cycle at a temperature of $28^{\circ} \mathrm{C}$. Embryos were developmentally staged according to Kimmel et al. (1995).

\section{Generation of constructs}

Generation of $-1696 \alpha 1$ TIpEGFP expression vector has previously been described (Hieber et al., 1998) and contains 1696 bp of $5^{\prime}$ flanking $\alpha 1$ tubulin DNA, exon 1, and the first intron fused in frame to the GFP sequence. This promoter fragment is referred to as wild-type (WT) in this manuscript. Mutant $\alpha 1$-tubulin promoters were produced by using wild-type and mutant oligonucleotide primers and PCR to generate mutant $\alpha 1$-tubulin promoter fragments that were subcloned to replace the corresponding fragment in the $1.696 \mathrm{~kb}$ promoter. All mutants were verified by DNA sequencing. $\triangle$ EHDGFP (EHD) and $\triangle$ HDGFP (HD) mutant promoters were obtained by respectively deleting a 64 ( -469 to $-406)$ or a $30(-439$ to -410$)$ nucleotide sequence within the $1696 \mathrm{bp}$ of $\alpha 1$-tubulin 5' flanking DNA.

\section{Generation of transgenic zebrafish}

DNAs were resuspended in injection buffer, and single-cell zebrafish embryos were injected as previously described (Hieber et al., 1998). Injected fish were bred and screened for reporter gene expression (Goldman and Ding, 2000; Goldman et al., 2001). Incorporation of the transgenic fragments and copy number were determined by Southern blotting.

\section{Surgery}

All animals were anesthetized in $0.02 \%$ tricaine methane sulfonate (Sigma, St. Louis, MO) before surgery.

Optic nerve lesions. Optic nerve crushes were performed as described previously (Hieber et al., 1998). Under microscopic visualization, the right eye was gently pulled from its socket, and the exposed optic nerve was crushed behind the eyeball using forceps. Care was taken not to lesion the ophthalmic artery running along the optic nerve, and fish exhibiting bleeding were not used. The left optic nerve was kept intact, its retina serving as an unoperated control. After surgery, fish were returned to their tanks for $1 \mathrm{~d}$ to 4 weeks. Some fish were sham-operated, with their optic nerves being only exposed.

Eye lesions. Under microscopic visualization, the right eye was gently pulled from its socket and stabbed once through the sclera with a 30 gauge needle. The needle was inserted to the length of the bevel $(\sim 5 \mathrm{~mm})$ to achieve similar depth lesion from case to case. After surgery, fish were returned to their tanks for $1 \mathrm{~d}$ to 4 weeks.

\section{RNA isolation and cDNA synthesis}

For RNA analysis, control and axotomized retinas were dissected from anesthetized, dark-adapted ( $>3 \mathrm{hr}$ ) adult transgenic fish, $7 \mathrm{~d}$ after unilateral optic nerve crush. Total RNA was isolated using TRIzol (Invitrogen, Carlsbad, CA) according to the manufacturer's protocol. RNA concentrations were spectrophotometrically estimated, and equivalent amounts ( $1 \mu \mathrm{g}$ of total RNA) were subjected to first strand cDNA synthesis using oligo-dT primers and Superscript II reverse transcriptase (Invitrogen, Carlsbad, CA) according to manufacturer's specifications.

\section{PCR analysis}

For each sample, $1 / 20$ of the total cDNA reaction was used in a radioactive PCR to amplify $\alpha 1$-tubulin and GFP transcripts. The $\alpha 1$-tubulin primer pair (forward: 5' CTG TAA GAT CTC TCC GCC AAG 3'; reverse: 5' GTG GAA CAG CTG ACG GTA TGT C 3') yields a 324 bp product corresponding to the endogenous $\alpha 1$-tubulin mRNA, whereas the GFP primer set (forward: 5' GAC GAC GGC AAC TAC AAG AC 3'; reverse: 5' GGT CAC GAA CTC CAG CAG GAC 3') (a gift from Dr. Steven Suhr, University of Michigan, Ann Arbor, MI) amplifies a 371 bp product from the transgene. As a normalizing control, primers that amplified a $400 \mathrm{bp}$ fragment of a housekeeping gene transcript, e-IF4 $\alpha$ (forward: 5' GCC CCT GCC AAT GTA 3'; reverse: 5' GGG CTT GCC AGG GAC 3') were used. PCR reactions were performed in an Eppendorf (Hamburg, Germany) Mastercycler gradient 5331, with Taq polymerase (Promega, Madison, WI) in the presence of $1.5 \mathrm{mM} \mathrm{MgCl}_{2}$ and $0.2 \mathrm{~mm}$ dNTPs spiked with $1 \mu \mathrm{Ci} \alpha-\mathrm{P}^{32} \mathrm{dCTP}$. The amplification profile used is as follows: $94^{\circ} \mathrm{C}, 1 \mathrm{~min} ; 56^{\circ} \mathrm{C}, 1 \mathrm{~min}$; and $72^{\circ} \mathrm{C}, 2 \mathrm{~min}$. To ensure linearity of amplification for each primer set, different cycling conditions were tested, and the final PCRs were performed at two nonsaturating cycles (19 and 22). Amplified samples were analyzed on an $8 \%$ native acrylamide gel and subjected to autoradiography. Finally, the signal intensities for each band (mean density $X$ area) were quantified using NIH Image 1.62 software (developed by the National Institutes of Health and available at http:// rsb.info.nih.gov/nih-image/). Final values were normalized to values of e-IF $4 \alpha$ internal control bands. Data are reported as the fold increase, thus providing an index of the magnitude of the axotomy-induced change in the abundance of the particular mRNA.

\section{Bromodeoxyuridine injections}

To identify dividing cells, bromodeoxyuridine (BrdU) injections were performed as previously described (Byrd and Brunjes, 2001). Briefly, after anesthesia in $0.02 \%$ tricaine methane sulfonate, control fish and fish in which the retina had been punctured $3 \mathrm{~d}$ earlier received a single intraperitoneal injection of $50 \mu \mathrm{l}$ of a $10 \mathrm{mg} / \mathrm{ml} \mathrm{BrdU}$ (Sigma) stock solution. Fish were subsequently kept in separate tanks for $4 \mathrm{hr}$ or $4 \mathrm{~d}$.

\section{Tissue preparation}

Fish were anesthetized by immersion in ice-cold water. Brains and eyes from adult and juvenile fish were dissected out, removed from the skull, and fixed by immersion in fresh $4 \%$ paraformaldehyde in $0.1 \mathrm{M}$ phosphate buffer (PB), pH 7.4, for $16 \mathrm{hr}$. Embryos were fixed in toto in the same fixative for $4 \mathrm{hr}$. After fixation, samples were either cryoprotected in phosphate-buffered 30\% sucrose (adults and juveniles) or cryoprotected in a gradient of sucrose (embryos, see Barthel and Raymond, 1990), before embedding with O.C.T. mounting medium (Sakura Finetek USA, Inc., Torrance, CA). Embedded samples were kept at $-70^{\circ} \mathrm{C}$ until sectioning. Eight micrometer horizontal, sagittal, or coronal serial sections were obtained on a cryostat (CM3050S; Leica, Nussloch, Germany), collected on Superfrost/Plus slides (Fisher Scientific, Pittsburgh, PA), dried overnight at room temperature, and stored at $-70^{\circ} \mathrm{C}$. Representative slides were then selected for immunohistochemistry.

\section{Immunohistochemistry}

The following primary antibodies were used: mouse anti-acetylated tubulin (1:1000; Sigma); rat anti-BrdU (dividing cell marker; 1:250; Harlan; Sera-Lab); goat anti-choline acetyltransferase (ChAT; amacrine cell marker; Yazulla and Studholme, 2001) (1:250; Chemicon, Single Oak 
A

rat: TTACAGTTGTATTATTGTGGTTATTATTATTATTACTATTATTATTAATA goldfish: GTTCAGATGTTATA. . . CAATAA. TAATAATAATAATAATAATAAATCC zebrafish: AGGCAAATGACACATTCCCAATAA. TAATAATAATAATAATAATAATAAT

B



Figure 1. A, Conserved E-box (CANNTG) and homeodomain consensus (TAAT) sequences are found when comparing a region of the goldfish $\alpha 1$-tubulin promoter (GenBank accession number AF002654) to a 3' end region of the zebrafish $\alpha 1$-tubulin gene (GenBank accession number BX248228) and to a region of the rat T $\alpha 1 \alpha$-tubulin gene promoter (GenBank accession number S76207). Note that the best alignment for the rat sequence is obtained when using the antisense strand of DNA. Dots within the sequence represent gaps for optimal alignment. $B$, EHD and HD mutant promoters were obtained by respectively deleting a 64 $(-469$ to -406$)$ (sequence boxed in gray) or a $30(-439$ to -410$)$ (sequence boxed in gray) nucleotide sequence within the 1696 bp of $\alpha 1$-tubulin $5^{\prime}$ flanking DNA.

Drive, PA); mouse Fret 11 (rod photoreceptor marker) and Fret 43 (double cone photoreceptor marker; Larison and Bremiller, 1990) (1:250; Zebrafish International Resource Center (ZIRC), Eugene, OR); mouse anti-GAP-43 (1:500; Sigma); mouse anti-glial fibrillary acidic protein (GFAP) (1:500; Chemicon); rabbit anti-GFP (1:1000; Molecular Probes, Eugene, OR); mouse anti-HuC/D (1/500; Molecular Probes); rabbit antiprotein kinase C (PKC; ON bipolar cell marker; Yazulla and Studholme, 2001) (1:250; Santa Cruz Biotechnology, Santa Cruz, CA); mouse antityrosine hydroxylase (TH; interplexiform cell marker; Yazulla and Studholme, 2001) (1:500; Chemicon); and mouse zrf1 (glial marker) (1:250; ZIRC). Control experiments were performed by omitting one of the immunoreagents of the immunohistochemical protocol sequence or replacing the primary antibody with normal serum. For BrdU immunostaining, sections were pretreated with $2 \mathrm{~N} \mathrm{HCl}$ for $30 \mathrm{~min}$ at $37^{\circ} \mathrm{C}$, two 5 min rinses in $0.1 \mathrm{~m}$ Borate buffer, and three, $10 \mathrm{~min}$ rinses in PBS, pH 7.4.

Primary antibodies were diluted in TBS containing $1 \%$ donkey serum and $0.3 \%$ Triton X-100 [normal donkey serum Triton (NDST) $1 \%$ ]. Cryostat sections were first rehydrated $10 \mathrm{~min}$ in TBS, preincubated in NDST 3\% for $1 \mathrm{hr}$ at room temperature, and then incubated in the primary antibodies overnight at $4^{\circ} \mathrm{C}$. Sections were rinsed three times in NDST $1 \%$ and incubated for $2 \mathrm{hr}$ at room temperature with secondary anti-mouse, anti-rabbit, anti-rat, or anti-goat antibodies conjugated to Alexa 488 (1:1000; Molecular Probes) or cyanin 3 (1:250; The Jackson Laboratory, West Grove, PA). Sections were then washed five times in PBS, with the third wash containing $10 \mathrm{ng} / \mathrm{ml} \mathrm{4,} \mathrm{6-diamidino-2-}$ phenylindole (DAPI; Sigma) for nuclear staining. Slides were then coverslipped using MOWIOL and subsequently stored in the dark at $4^{\circ} \mathrm{C}$.

\section{Imaging}

Fluorescence and immunofluorescence images were visualized, examined, and captured by using a digital camera adapted onto a Zeiss (Oberkochen, Germany) Axiophot fluorescence microscope. Exposure parameters were kept constant throughout each experiment. Microphotographs and illustrations were composed and annotated by using Adobe Photoshop 6.0.

\section{Quantification of GFP immunofluorescence}

NIH Image software (version 1.32) (developed by the NIH and available at http://rsb.info.nih.gov/nih-image/) was used to quantify GFP immunofluorescence intensity in the retinal ganglion cell layer from adult transgenic zebrafish, $7 \mathrm{~d}$ after unilateral optic nerve crush. Retinas on both the control and crushed sides were evaluated (three retinas per side for each transgene). For each retina, 10 random fields ( $40 \times$ objective) representative of the whole ganglion cell layer were analyzed. Exposure levels were primarily adjusted to avoid saturation and maintained constant throughout the experiment. For each field analyzed, a fixed-sized box was drawn inside the ganglion cell layer, and the average pixel density (arbitrary units) was measured, then the average background pixel density of the image analyzed was subtracted.

Statistical significance

The degree of statistical significance withingroup control-to-crush comparison was determined by computer on the basis of paired Student's $t$ test. Statistical significance was defined at $p<0.05$.

\section{Results}

Generation of transgenic animals

Comparison of fish and rat $\alpha 1$-tubulin genes identified a conserved region of DNA harboring a repetitive HD sequence (TAAT) and a nearby E-box (CANNTG) (Fig. 1A). To characterize sequences of the $\alpha 1$-tubulin promoter that regulate gene expression during regeneration, we generated stable lines of transgenic fish expressing GFP under the control of two different mutant $\alpha 1$-tubulin promoters and compared them to control $-1696 \alpha 1$ TIpEGFP transgenic fish. The $-1696 \alpha 1$ TIpEGFP transgenic lines have previously been generated and described (Goldman et al., 2001) and will be referred to as wild-type (WT) transgenic lines. The first mutant promoter, named EHD, carries a deletion of both the putative E-box (E) and homeodomain (HD) sequences $(-469$ to -406$)$ (Fig. $1 B$ ). The second mutant promoter, named HD, carries a deletion of only the HD sequence $(-439$ to -410$)$ (Fig. $1 B$ ). Transgenic fish were generated by injecting DNA into single-cell zebrafish embryos. Ten independent EHD and four independent HD founders were isolated by screening the F1 progeny of injected fish for GFP expression. Positive F1 animals were then bred to wild-type fish to establish transgenic lines. Individual lines were subsequently characterized by Southern blot analysis to confirm transgene integration and determine copy numbers. Lines of any particular transgenic fish overall exhibited similar patterns of GFP expression, although expression levels varied. For each transgene, two independent lines were kept for further analysis; therefore, lines 2 and 3 of $-1696 \alpha 1$ TIpEGFP (referred to as WT2, WT3) were compared with lines 1 and 10 of EHD (EHD1, EHD10) and lines 2 and 4 of $\mathrm{HD}$ (HD2, HD4).

\section{Characterization of GFP expression in the developing and adult retina of WT, EHD, and $\mathrm{HD}$ transgenic zebrafish}

The zebrafish retina displays a well defined laminated cytoarchitecture, which consists of three cellular (nuclear) layers separated by two neuritic (plexiform) layers (Figs. 2, 3). The photoreceptors are located in the outer nuclear layer (ONL), the bipolar, horizontal, amacrine, interplexiform, and glial Müller cell somata are contained within the inner nuclear layer (INL), and the RGCs, as well as a few displaced amacrine cells constitute the retinal ganglion cell layer (GCL). Axonal and dendritic processes are distributed in the outer plexiform layer (OPL) and the inner plexiform layer (IPL), with the exception of the RGC axons, which extend within the optic fiber layer. Retinal development in the zebrafish follows a sequence similar to, but faster than, other vertebrates, so that by $3 \mathrm{~d}$ of development all major retinal cell types can be distinguished (Malicki, 1999; Schmitt and Dowling, 1999). We have previously shown that the $\alpha 1$-tubulin promoter is active in the developing zebrafish retina, particularly in the RGCs (Hieber et al., 1998; Goldman et al., 2001). Therefore, we 
first sought to determine whether $\alpha 1$ tubulin promoters with deletions of the E-box and/or the HD would also be active in the developing retinas, by analyzing and comparing the distribution pattern of GFP expression in the retinas of WT, EHD, and HD transgenic fish from $24 \mathrm{hr}$ to 4 weeks after fertilization ( $n=12-15$ per age and per line). The differentiated state of the retina was assessed using immunostaining for acetylated tubulin, a marker for differentiated axons (Chitnis and Kuwada, 1990; Wilson et al., 1990) (Fig. 2).

By $24 \mathrm{hr}$ after fertilization (hpf), the eye cup has already developed and consists of an actively dividing retinal epithelium (Fig. 2) (Malicki, 1999; Schmitt and Dowling, 1999). Retinal cells were undifferentiated at this stage, as indicated by the absence of immunoreactivity for acetylated tubulin (Fig. 2). Corroborating our previous observations (Goldman et al., 2001), and as shown in Figure 2, the retinal neuroepithelium of WT transgenic fish exhibited GFP immunoreactivity. Columns of cells strongly positive for GFP could be distinguished extending through the thickness of the epithelium over a background of more weakly stained cells. The overall distribution patterns of GFP expression in the retinal neuroepithelia of EHD and HD retinas were similar to that observed for fish expressing the WT promoter, although the expression levels were more heterogeneous. Specifically, the number of retinal cells exhibiting a robust intensity of GFP immunostaining was reduced in the mutant transgenic fish (Fig. 2).

Between 24 and $48 \mathrm{hpf}$, lamination of the retina progressively developed along with cell differentiation so that by $48 \mathrm{hpf}$ all major retinal layers and acetylated tubulin immunostaining was observed (Fig. 2). At $48 \mathrm{hpf}$, the retinas of WT transgenic fish exhibited high levels of GFP expression in cells with neuronal-like morphology, which were located in the GCL, the INL, and more occasionally the ONL (Fig. 2). Retinal cells immunoreactive for GFP exhibited various intensities of staining ranging from weak to strong, reflecting various levels of transgene expression. Notably, the RGCs, the first retinal cells to differentiate (Malicki, 1999; Schmitt and Dowling, 1999), displayed strong GFP-positivity. Compared with WT, the distribution pattern of GFP fluorescence throughout the retinas of both EHD and HD fish demonstrated a more heterogeneous appearance, because of the increase of cells displaying a low-to-medium intensity of immunoreactivity (Fig. 2). Whereas RGCs with high levels of GFP expression could be found in both HD and EHD retinas, they were clearly less numerous. As shown in Figure 2, the overall pattern and levels of GFP expression in WT, EHD, and HD transgenic fish were maintained up to $72 \mathrm{hpf}$, at which time differentiation and synaptogenesis are basically completed in the retina (Malicki, 1999; Schmitt and Dowling, 1999).

At 1 week after fertilization (wpf), a dramatic decrease in the levels of GFP expression was observed throughout the retinas of both WT and mutant transgenic zebrafish (Fig. 2). In WT retinas, GFP expression became more restricted to cells in the INL and

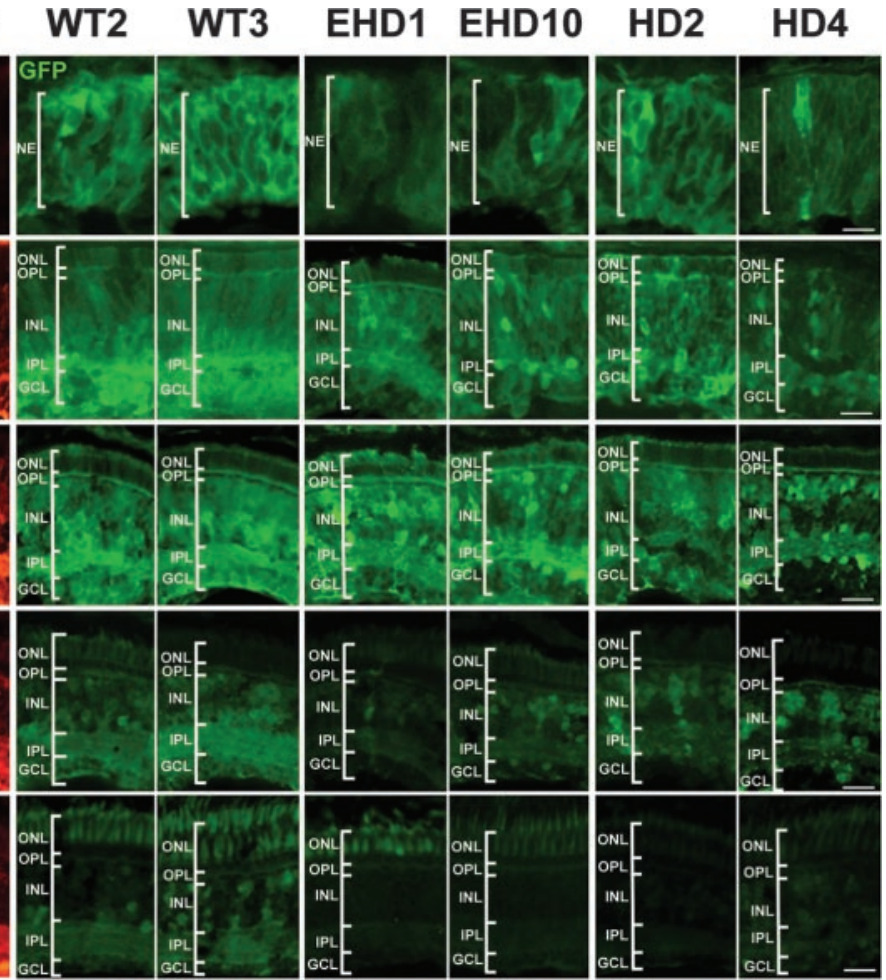

Figure 2. Microscopic analysis of GFP immunostaining in transversal sections through the developing retinas of WT2, WT3, EHD1, EHD10, HD2, and HD4 transgenic zebrafish at 24, 48, and $72 \mathrm{hpf}$ and 1 and 4 wpf. Retinal cytoarchitecture and differentiation state of the developing retinas are illustrated, respectively, with DAPI staining and acetylated tubulin (AcTub) immunofluores-

rare scattered cells in the ONL. Although some GFP positivity could still be detected in a few RGCs, it was of low intensity. GFP immunoreactivity was also diminished in both EHD and HD retinas at $1 \mathrm{wpf}$, with the exception of a few robustly GFP-positive cells (Fig. 2).

At 4 wpf (Fig. 2), GFP expression levels continued to decrease throughout the layers of WT, EHD, and HD retinas, with the EHD fish exhibiting the faintest intensity of immunostaining. The distribution pattern of GFP expression appeared quite similar between WT and both EHD and HD retinas, consisting of some GFP-positive cells in the ONL and the INL. Whereas a few weakly stained cells could still be observed in the GCL of WT and HD fish, none could be detected in the GCL of EHD retinas (Fig. 2 ). At this time point, GFP-positive cells were also found at the periphery of the retina, namely the circumferential germinal zone (CGZ), known to generate most of the retinal cells (for review, see Otteson and Hitchcock, 2003). Whereas high levels of GFP expression were observed in the CGZs of WT and HD transgenic fish, they were much weaker in EHD fish (data not shown).

At 5 month after fertilization, as illustrated for WT2, the distribution pattern of GFP expression in WT transgenic fish was overall similar to that observed at 4 wpf. Cells with the highest levels of GFP expression were mostly found in the inner part of the INL, at the boundary with the IPL (Fig. 3B, arrows), and in the CGZ (Fig. $3 G$ ). Some scattered cells were also found in the inner part of the ONL (Fig. 3B, arrowheads). GFP-positive fibers were also observed throughout the thickness of the IPL, with a higher density in its inner part, and the OPL. Because our regeneration studies were to be performed in the adult zebrafish, we attempted to further identify the GFP-expressing cells. Double immunostaining of GFP with neuronal (HuC/D, Fret 11, Fret 43, TH, 



Figure 3. Microphotographs of horizontal sections through a 5-month-old retina of WT2 $(A, B, G, J-R)$, EHD10 $(C, D, H)$, and HD2 $(E, F, I)$ transgenic zebrafish. $A, C, E$, DAPI staining illustrating the retinal cytoarchitecture. $B$, Immunoreactivity for GFP illustrating the presence of GFP-positive cells in the ONL (arrowheads) and INL (long arrows) of the WT2 adult retina. D, F, Immunoreactivity for GFP illustrating the absence of GFP-expressing cells in the adult retinas of EHD10 (D) and HD2 (F). G-I, Immunoreactivity for GFP in the circumferential germinal zone of WT2 $(G)$, EHD10 $(H)$, and HD2 $(I)$ adult retinas. Note the significantly weaker staining in $H$ and $/$ compared with $G$. $J-R$, Microscopic analysis of GFP (green) $(J, M, P)$, HuC/D (red) $(K)$, TH (red) $(N)$, and BrdU (red) $(Q)$ immunostaining in the INL $(J-0)$ and the $0 \mathrm{NL}(P-R)$ of WT2 retina. Merged pictures illustrate the association (orange-yellow $=$ red plus green) of GFP with $\mathrm{HuC} / \mathrm{D}(L), \mathrm{TH}(0)$, and $\mathrm{BrdU}(R)$ in cells indicated by arrowheads in $J-R$. Scale bars: (in $F$ ) $A-F, 23.5 \mu \mathrm{m}$; (in I) $G-I, 26.6 \mu \mathrm{m}$; (in $R) J-R, 12 \mu \mathrm{m}$.

protein kinase $\mathrm{C}$, and ChAT) or glial (GFAP, Zrf-1) markers revealed that a subset of GFP-positive INL cells were positive for $\mathrm{HuC/D}$ (an early neuronal marker) (Fig. 3J-L), TH (a marker for dopaminergic interplexiform cells) (Fig. 3M-O), and more rarely with PKC (a marker for ON bipolar neurons) (data not shown). In contrast, GFAP or Zrf-1 staining was never found in GFPpositive cells, suggesting that they were not glia. Because neurogenesis persists in the adult fish retina (Otteson and Hitchcock, 2003), we analyzed the retinas of WT zebrafish $4 \mathrm{hr}$ or $4 \mathrm{~d}$ after administration of BrdU. A small number of BrdU-labeled nuclei were found in the adult retina mostly locating in the CGZ and in the inner part of the ONL. As illustrated for the ONL in Figure $3 P-R$, a few BrdU-positive nuclei were also GFP-positive, indicating $\alpha 1$-tubulin promoter activity in cells that were, or had been in a mitotic state. In contrast to fish expressing a WT promoter, the pattern of GFP expression in the retinas of EHD and HD zebrafish (illustrated respectively for EHD10 and HD2) was significantly different. Whereas numerous GFP-positive cells were found within the WT retina, EHD and HD retinas displayed very low, if any, GFP expression. As illustrated in Figure 3, D and $F$, no GFP positivity could be detected within the retinal layers of adult EHD and HD fish, with the exception of a few cells in the CGZ that displayed low GFP expression (Fig. 3H,I). $\alpha 1$-Tubulin promoter activity in the axotomized retina of $\mathrm{WT}, \mathrm{EHD}$, and HD adult transgenic zebrafish

In the adult zebrafish, $\alpha 1$-tubulin expression has been shown to accompany regrowth of RGC axons after optic nerve crush (Burrell et al., 1978; Hieber et al., 1998; Bormann et al., 1998; Goldman et al., 2001). To determine to what extent the E-box and HD elements contribute to $\alpha 1$ tubulin expression in this nerve regeneration model, we first analyzed and compared the distribution pattern of GFP immunoreactivity in the retinas and optic nerves of WT2 $(n=30)$, EHD10 $(n=20)$, and HD2 $(n=26)$ transgenic fish at various time points after optic nerve crush (Fig. 4). Successful optic nerve crush was assessed using immunostaining for GAP43, a protein also expressed by the regenerating RGC axons in the fish (Perry et al., 1987; Bormann et al., 1998). All cases displaying partial nerve crush, as evidenced by a partial GAP-43 immunostaining of the regenerating optic nerve, were discarded from the study.

As mentioned above, GFP staining was rarely observed in the RGCs of normal adult WT2 transgenic fish (Fig. 3B). GFP staining was also virtually undetectable in the RGCs of sham-operated fish (data not shown) or fish in which the optic nerve had been crushed $24 \mathrm{hr}$ earlier (Fig. 4). However, $2 \mathrm{~d}$ after surgery, GFP immunoreactivity was clearly visible in numerous RGCs, indicative of $\alpha 1$-tubulin promoter activation (Fig. 4). GFP expression continued to increase over time, so that by $3 \mathrm{~d}$ after axotomy, all RGCs were GFPpositive (Fig. 4). Levels of GFP staining in the RGCs peaked by $7 \mathrm{~d}$ after crush and noticeably decreased by 2 weeks to become almost undetectable by 4 weeks after crush (Fig. 4). GFP-positive fibers were detected in the optic nerve as early as $2 \mathrm{~d}$ after the lesion and could be seen coursing within the optic nerve, crossing the optic chiasma, and reaching the optic tectum by $7 \mathrm{~d}$ (Fig. $5 A$ ). The distribution pattern of GFP immunoreactivity in the regenerating optic nerve and tract mimicked the distribution pattern observed for GAP-43 (Fig. 5A,B). Close examination of the optic nerve and tract on the side of the crush also revealed the presence of some GFP-positive cells, whose presence was progressively masked by the robust GFP immunostaining of regrowing axons (Fig. 5A, arrowheads).

The distribution pattern of GFP immunoreactivity after optic nerve crush in the retinas of fish expressing mutant promoters was strikingly different from that observed in WT2 transgenic fish. Whereas WT2 retinas displayed robust GFP staining in the axotomized RGCs, no GFP expression could be detected in the RGCs of adult EHD10 fish after optic nerve crush at any time points examined (Fig. 4). As a result, no GFP positivity was present in the optic nerve and tract (Fig. 5C), despite successful optic nerve crush, as indicated by GAP-43 immunostaining (Fig. $5 D)$. We then analyzed GFP expression in the retina of HD2 fish after optic nerve crush, as shown in Figure 4. Whereas no GFP 
expression was observed in the RGCs before $2 \mathrm{~d}$ after crush, at day 2, some RGCs displayed GFP positivity, although at very low levels. At 3 d after crush, a larger number of RGCs displayed low to medium intensity of GFP staining with a few scattered cells that were robustly positive, and by $7 \mathrm{~d}$, most of RGCs displayed a low-tomedium GFP intensity, whereas a small subset displayed robust GFP immunopositivity (Fig. 4). Examination of the optic nerve revealed the presence of GFPpositive axons and cells (Fig. 5E,F). The apparent number of RGCs stained and the intensity of GFP staining progressively decreased thereafter, so that by 2 weeks after crush GFP expression was undetectable using immunohistochemistry (Fig. 4).

To address the issue of whether differences in GFP expression observed in axotomized EHD10 and HD2 retinas could be caused by an integration site effect, we subsequently examined and compared the distribution pattern of GFP immunoreactivity in the retinas of WT2, WT3, EHD1, EHD10, $\mathrm{HD} 2$, and HD4 transgenic fish, $7 \mathrm{~d}$ after optic nerve crush. As shown in Figure $6 A$, both WT2 and WT3 fish displayed robust GFP immunoreactivity in the axotomized RGCs, although expression levels appeared somewhat lower in WT3 fish. In contrast, and as previously observed in EHD10 fish, no GFP immunoreactivity could be detected in the axotomized RGCs of EHD1 fish after optic nerve crush (Fig. 6A). Analysis of GFP immunostaining in HD4 axotomized retinas revealed a distribution pattern similar to that observed for HD2 fish, although with lower expression levels (Fig. 6A). GFP immunofluorescence was restricted to numerous RGCs with medium to weak intensity of staining occasionally seeded with more robustly stained RGCs (Fig. 6A).

To evaluate the magnitude of the axotomy-induced changes in GFP expression observed in the RGCs for each transgenic line, we determined quantitatively the average GFP immunofluorescence intensity in both control and axotomized RGCs, $7 \mathrm{~d}$ after optic nerve crush (Fig. $6 B)$. Quantitative analysis revealed a statistically significant increase in the mean levels of GFP immunofluorescence in the RGCs between control and crushed sides in the WT2 (control: $3.04 \pm 0.86, n=3$; axotomized: $39.34 \pm 6.05, n=3 ; t=6.48 ; p<$ $0.02 ; 12.9$-fold increase), WT3 (control:

$3.03 \pm 0.56, n=3$; axotomized: $26.06 \pm 1.77, n=3 ; t=14.02$; $p<0.005$; 8.6-fold increase), HD2 (control: $1.89 \pm 0.33, n=3$; axotomized: $7.54 \pm 0.33, n=3 ; t=25.74 ; p<0.002 ; 3.99$-fold increase), and HD4 (control: $3.24 \pm 0.55, n=3$; axotomized: $11.63 \pm 0.64, n=3 ; t=20.46 ; p<0.003 ; 3.59$-fold increase) $111 \mu \mathrm{m}$.

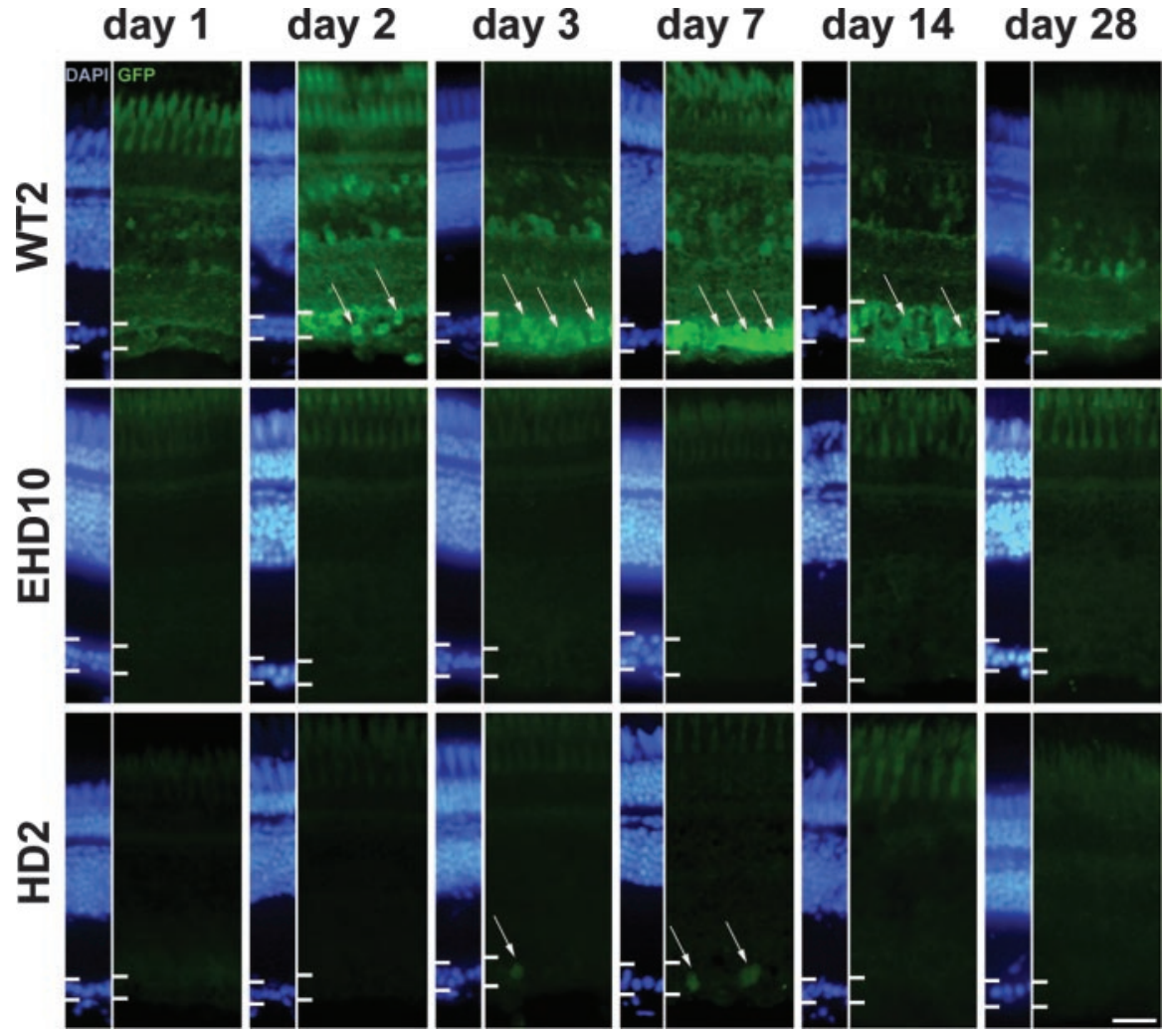

Figure 4. Microphotographs of horizontal sections through the regenerating retina of adult WT2, EHD10, and HD2 transgenic fish 1,2,3,7,14, and $28 \mathrm{~d}$ after unilateral optic nerve crush. The retinal cytoarchitecture is illustrated with DAPI staining. White bars delineate the ganglion cell layer. Immunostaining for GFP demonstrates the presence of numerous GFP-positive cells (arrows) in the ganglion cell layer of WT2 fish, as early as $2 \mathrm{~d}$ after axotomy. GFP-positive cells are also observed from 3 to $7 \mathrm{~d}$ after crush in the ganglion cell layer of HD2 transgenic fish. In contrast, note the absence of GFP immunoreactivity in the ganglion cell layer at all time points examined in EHD10 fish. Scale bar, $24 \mu \mathrm{m}$.


Figure 5. Microphotographs of horizontal sections through the optic chiasma of adult WT2 $(A, B), \operatorname{EHD10}(C, D)$, and HD2 $(E, F)$ transgenic zebrafish, $7 \mathrm{~d}$ after unilateral optic nerve crush. Immunostaining for GFP $(A, C, E)$ and GAP-43 $(B, D, F)$. Note the GFP immunostaining in the optic nerve and tract of WT2 and HD2 fish; in contrast, no GFP expression can be detected in EHD10. Asterisks indicate the crushed optic nerve. Arrowheads in $A$ and $E$ indicate the presence of GFP-positive cells. Scale bar, transgenic fish. In contrast, no statistically significant differences were found in EHD1 (control: $1.79 \pm 0.26, n=3$; axotomized: $1.82 \pm 0.12, n=3 ; t=0.12 ; p>0.05$ ) and EHD10 (control: $1.85 \pm 0.28, n=3$; axotomized: $1.77 \pm 0.47, n=3 ; t=0.35 ; p>$ $0.05)$ transgenic fish. 
A
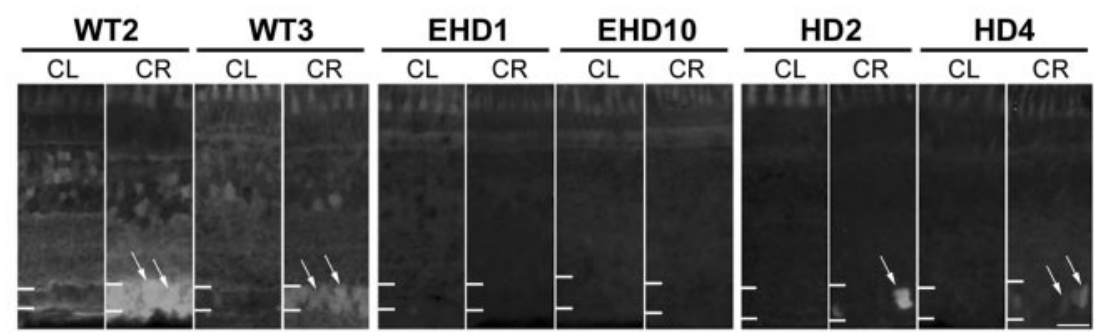

B
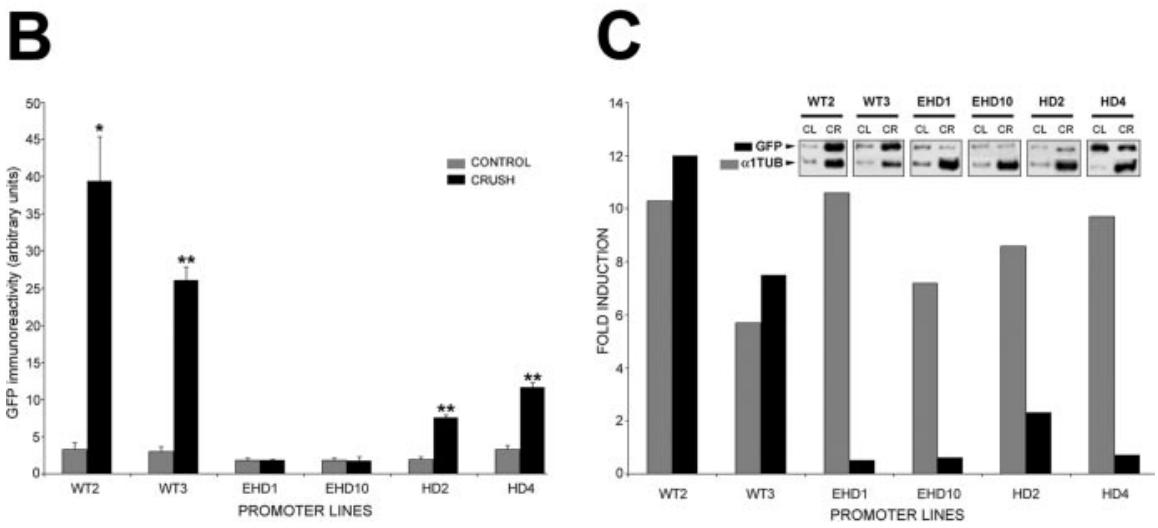

Figure 6. A, Microphotographs of horizontal sections through the retinas of adult WT2, WT3, EHD1, EHD10, HD2, and HD4 transgenic fish $7 \mathrm{~d}$ after unilateral optic nerve crush. Immunoreactivity for GFP is illustrated for retinas from both the control (CL) and crushed (CR) sides. White bars delineate the ganglion cell layer. Note the presence of GFP-positive cells (arrows) in WT2, WT3, HD2, and HD4 axotomized retinas. Scale bar, $28.9 \mu \mathrm{m}$. B, Quantitative image analysis of the mean intensity of GFP immunoreactivity in the ganglion cell layer of adult WT2, WT3, EHD1, EHD10, HD2, and HD4 transgenic fish $7 \mathrm{~d}$ after unilateral optic nerve crush. Histogram values represent mean \pm SEM. Asterisks indicate within-group statistically significant differences $\left({ }^{*} p<0.05\right.$; ${ }^{* *} p<$ 0.01 , paired Student's $t$ test) between control and crushed sides. C, RT-PCR semiquantitative analysis of endogenous $\alpha 1$-tubulin ( $\alpha 1$ TUB) and GFP transgene mRNAs in the retinas of adult WT2, WT3, EHD1, EHD10, HD2, and HD4 transgenic fish $7 \mathrm{~d}$ after unilateral optic nerve crush. For each transcript, induction is expressed as the signal intensity obtained from the retina on the crushed side (CR) divided by the signal intensity obtained from the retina on the control side (CL). Values were normalized to values from the e-IF4 $\alpha$ internal control bands (data not shown).

To address the possibility that an increase in GFP immunoreactivity in the axotomized RGCs was missed in the EHD transgenic fish because of expression levels below the threshold of immunodetection, a semiquantitative mRNA analysis for the GFP transgene and endogenous $\alpha 1$-tubulin was performed on the retinas of WT2, WT3, EHD1, EHD10, HD2, and HD4 transgenic fish, $7 \mathrm{~d}$ after optic nerve crush. As illustrated in Figure $6 C$, an increase in $\alpha 1$-tubulin mRNA levels was consistently observed in the retinas of all transgenic lines on the side of the optic nerve crush, indicative of the success of the lesion. Increases in GFP mRNA levels were also detected in the axotomized retinas of WT2 (12-fold increase), WT3 (7.5-fold increase), and HD2 (2.3fold increase) transgenic fish, but not in the axotomized retinas of EHD1, EHD10, and HD4 fish (Fig. 6C).

\section{$\alpha 1-T u b u l i n$ promoter activity in the lesioned retina of WT,} EHD, and HD adult transgenic fish

We next sought to examine whether the E-box and HD elements also played a role in $\alpha 1$-tubulin expression in another regeneration model by analyzing the distribution pattern of GFP immunoreactivity in the retinas of WT2, WT3, EHD1, EHD10, HD2, and HD4 transgenic fish at various time points after mechanical lesion of the retina.

As illustrated in Figure $7 \mathrm{~A}$ for fish expressing the WT promoter, histological analysis of retinal sections revealed that $24 \mathrm{hr}$ after puncture of the retina, the lesion site could clearly be identified by the displacement and interruption of the retina laminar organization. The lesion cavity often appeared filled with a disorganized amalgam of pigmented and nonpigmented cells that extended up to, and protruded into, the vitreal chamber. Close examination of DAPI staining revealed the presence of pyknotic nuclei, indicating cell loss (Fig. $7 A$, inset). By $7 \mathrm{~d}$ after retinal puncture, the injured retina appeared to have almost completely regenerated, as indicated by the restoration of a continuous laminated structure. A shear in the retinal tissue was the only indication of a former lesion (Fig. 7B). By 4 weeks, the last time point examined, the lesioned retina was histologically indistinguishable from the control retina (Fig. 7C).

Up to $3 \mathrm{~d}$ after injury, the distribution pattern of GFP expression in the lesioned retina of WT transgenic fish did not differ significantly from that observed in the control untouched retina, with the exception of some displaced GFP-positive cells that could be seen along and within the needle track (data not shown). In contrast, $3 \mathrm{~d}$ after puncture, densely packed cells and processes robustly positive for GFP could be observed within, and lateral to, the lesion site (Fig. 7D, G). This area of increased GFP expression extended up to $\sim 200 \mu \mathrm{m}$ along the dorsoventral axis. GFP-positive cells were mainly distributed within the ONL and the INL and displayed various morphologies, most of them reminiscent of glial cell types. The overall pattern and levels of GFP expression were maintained up to 1 week after puncture, but could no longer be detected by 4 weeks (last time point examined) (data not shown).

In contrast to the optic nerve regeneration model, examination of the punctured retinas in EHD and HD transgenic zebrafish revealed a time course and distribution pattern of GFP expression approximating the pattern observed in WT transgenic fish. As shown in Figure 7, cells displaying high levels of GFP immunoreactivity were readily observed in the lesioned retinas of both EHD (Fig. 7E,H) and HD (Fig. 7F,I) fish at $3 \mathrm{~d}$ after puncture. The density of GFP-positive cells in punctured EHD and HD retinas appeared lower than that observed for WT (Fig. 7, compare $E, F, H, I$ with $D, G)$, mostly because of the absence of GFP expression in unlesioned retinas harboring mutant transgene promoters.

Because they normally display very modest, if any, basal GFP expression, and because they lack elements necessary to promoter activity during axon regeneration, EHD and HD retinas were chosen for further characterization of the cells expressing GFP after retinal injury. Double-immunostaining with the neuronal marker $\mathrm{HuC} / \mathrm{D}$ indicated that a small percentage of GFPpositive cells were neurons (data not shown). Immunological staining with glial markers (GFAP, Zrf-1) confirmed that a significant contingent of GFP-expressing cells and fibers colocalized or associated with these markers and displayed a characteristic 
Müller glia-like phenotype, as evidenced by their cell bodies sitting in the INL and sending long processes to the inner and outer membranes (Fig. $7 J-L, P$ ). As illustrated in Figure $7 \mathrm{M}-\mathrm{O}$, some GFPpositive glial-like cells could also be observed in the OPL and the ONL after retinal lesion. It should be noted that some GFP-positive cells did not seem to stain for any of the neuronal or glial markers used in this study. Analysis of the retinas $3 \mathrm{~d}$ after puncture and $4 \mathrm{hr}$ after BrdU injections revealed numerous BrdU-positive nuclei sitting in both the ONL and the INL (Fig. 7Q) and the CGZ (data not shown). A number of GFP-positive cells, some of which exhibited Müller glia-like morphology, were also immunoreactive for BrdU (Fig. $7 P-R$, arrows), confirming thereby that they were, or had been, actively dividing.

\section{Discussion}

We chose a transgenic approach to investigate and identify promoter elements responsible for $\alpha 1$-tubulin gene induction in the regenerating visual system of the adult zebrafish. We found that a $64 \mathrm{bp}$ $(-469$ to $-406 \mathrm{bp})$ region of the $\alpha 1$ tubulin promoter contains elements that are necessary to drive reporter gene expression in adult RGCs after optic nerve crush, but are not essential for promoter activation in the developing retina, or in the adult retina after mechanical eye injury. To our knowledge, this is the first report identifying a specific DNA sequence that responds to signals necessary for successful CNS regeneration in vivo.

Understanding the molecular signals that regulate the transcription of genes favoring axonal growth and elongation will help us to better understand the regenerative process, and may lead ultimately to ameliorating the deleterious effects of CNS injury. We have previously shown that a $1.696 \mathrm{~kb}$ upstream fragment of the goldfish $\alpha 1$-tubulin promoter along with its first intron was capable of driving GFP expression in the developing and regenerating zebrafish CNS in a pattern mimicking the endogenous $\alpha 1$-tubulin gene (Hieber et al., 1998; Goldman et al., 2001). Comparison of fish and rat $\alpha 1$-tubulin promoters identified a conserved region with a repetitive $\mathrm{HD}$ sequence (TAAT) and a nearby E-box (CANNTG) (Hieber et al., 1998), which led us to speculate that it could be of importance for regulating $\alpha 1$-tubulin gene transcription. To uncover the significance of this conserved sequence, we used the GFP reporter gene as a marker of expression and fused it to two
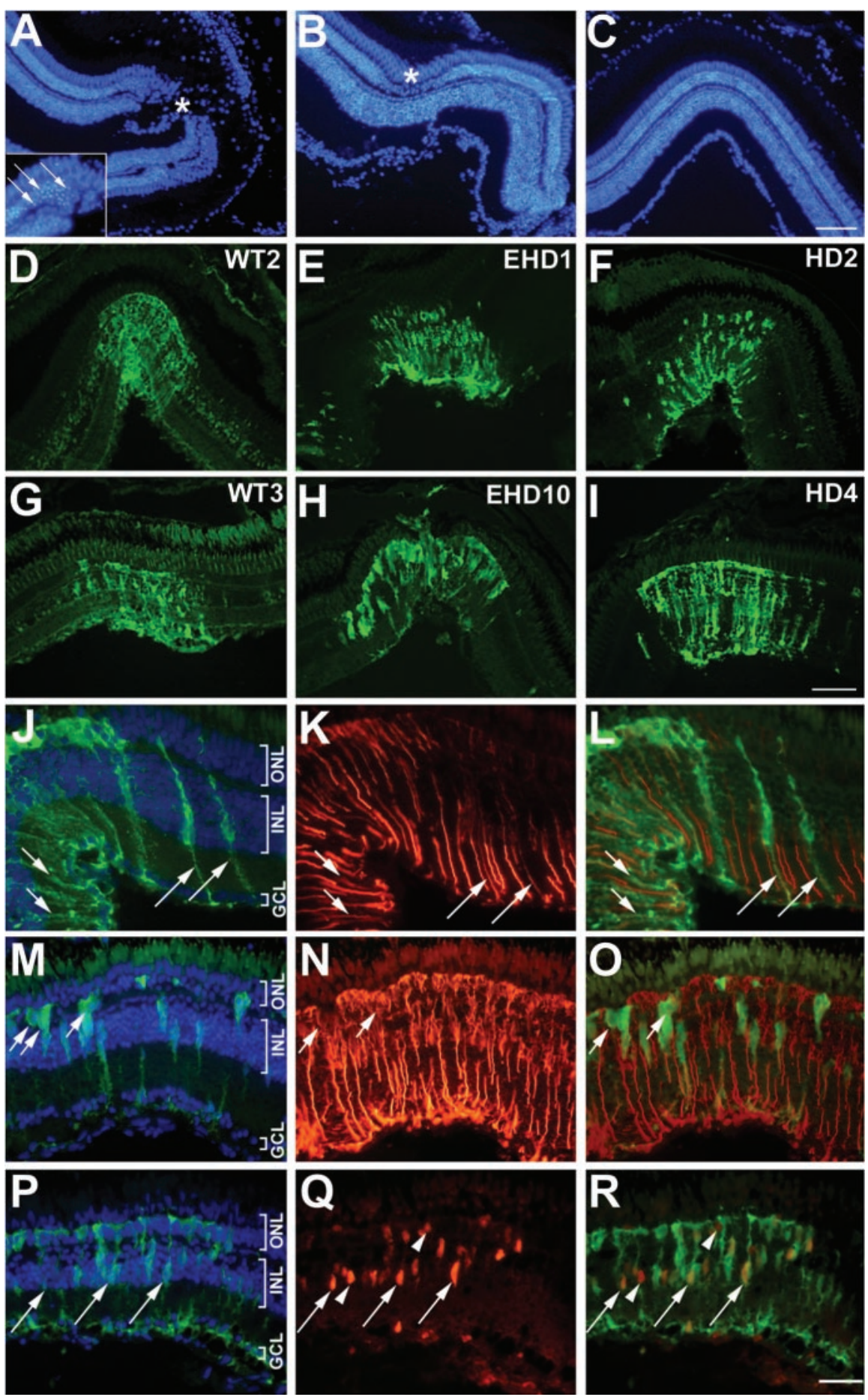

Figure 7. Microphotographs of horizontal sections through the retina of adult WT2, WT3, EHD1, EHD10, HD2, and HD4 transgenic zebrafish at $24 \mathrm{hr}, 3 \mathrm{~d}, 7 \mathrm{~d}$, and 4 weeks after retinal puncture. The retinal cytoarchitecture is illustrated with DAPI staining $A-C$, DAPI staining of the WT2 retina at $24 \mathrm{hr}(A), 7 \mathrm{~d}(B)$, and 4 weeks ( $C$ ) after retinal puncture. The lesion site (asterisk) is clearly visible up to $7 \mathrm{~d}$ after retinal injury. The inset in $A$ illustrates pyknotic profiles (arrows). $D-I$, Immunoreactivity for GFP in the lesioned retinas of WT2 (D), WT3 (G), EHD1 (E), EHD10 (H), HD2 (F), and HD4 (I) $3 \mathrm{~d}$ after injury. J-L, Merged picture (L) illustrates the association of GFP (green; $J$ ) with the glial marker zrf- 1 (red; $K$ ) in the lesioned retina of HD2, $3 \mathrm{~d}$ after injury. Note the presence of numerous double-immunostained (orange-yellow = red plus green) processes (arrows). $M-0$, Merged picture ( 0 ) illustrates the association of GFP ( $g r e e n ; M$ ) with the glial marker zrf- 1 (red; $N$ ) in the lesioned retina of EHD10, $3 \mathrm{~d}$ after injury. Note the presence of numerous double-immunostained (orange-yellow $=$ red plus green) processes (arrows). Notice also that GFP-positive glia-like cells localize in the INL, the $0 \mathrm{PL}$, and the $0 \mathrm{NL}(M) . P-R$, Merged picture $(R)$ shows that $3 \mathrm{~d}$ after injury and $4 \mathrm{hr}$ after administration of BrdU, some BrdU-positive cells (red; $Q$ ) are associated (orange-yellow = red plus green) (arrows) with GFP (green; $P$ ) in the retina of HD2 fish, whereas others are not (arrowheads). Scale bars: (in C) A-C, $101 \mu \mathrm{m}$; (in /) D-l, $77.5 \mu \mathrm{m}$; (in $R$ ) $J-R, 15 \mu \mathrm{m}$. 
deletion mutants (EHD and HD) of the $1.696 \mathrm{~kb} \alpha 1$-tubulin promoter (WT). We focused our analysis on the zebrafish visual system because it develops rapidly and displays remarkable capabilities of regeneration (Bernhardt, 1999).

We first investigated whether $\alpha 1$-tubulin promoters with deletions of the E-box and/or the HD would also be active in the developing retinas, and more particularly in the RGCs. We show robust GFP expression in the developing retinas of WT, EHD, and HD transgenic fish, although with differences in the time course and intensity, suggesting that sequences within the EHD region are required for regulating $\alpha 1$-tubulin expression levels in developing retinas. We also show that in adult WT transgenic fish GFP expression is maintained in some retinal neurons, mainly in the CGZ, the INL, and to a lesser extent in the ONL. GFP-positive INL cells included dopaminergic interplexiform cells and ON bipolar cells. Some GFP-positive cells in the ONL also exhibited staining for the mitotic marker BrdU, suggesting that they might correspond to the previously described rod precursors (Otteson and Hitchcock, 2003). Neural progenitor cells have been reported to express $\alpha 1$-tubulin in the adult CNS of zebrafish and mammals (Wang et al., 1998; Gloster et al., 1999; Goldman et al., 2001). Whereas robust immunoreactivity for GFP was observed in WT retinal layers, none could be detected in fish carrying mutant promoters. These data suggest that a regulatory element contained within the $64 \mathrm{bp}$ sequence deleted from the $\alpha 1$-tubulin promoter is required for gene expression in adult retinas. The observation that the HD sequence is missing from both mutant promoters suggests that it is the key regulatory element, although other contributing elements could also be located immediately flanking the HD sequence.

We have confirmed that our WT transgene contains sufficient information for activating the $\alpha 1$-tubulin promoter in zebrafish RGCs after unilateral optic nerve crush (Hieber et al., 1998; Goldman and Ding, 2000; Goldman et al., 2001). Robust GFP expression is induced in the axotomized RGCs as early as $2 \mathrm{~d}$ after optic nerve crush, peaks by $7 \mathrm{~d}$, and starts decreasing thereafter, corroborating previous mRNA studies (Bormann et al. 1998; Goldman et al., 2001). Interestingly, upregulation of GFP expression was also observed in a subset of cells and fibers with glial-like morphology, which were located in the regenerating optic nerve and tract. Although the identity of these cells remains to be determined, the observation that GFP positivity did not associate with either neuronal or astrocytic markers (data not shown) indicates a possible oligodendrocytic phenotype. The observation of GFP expression in optic tract/nerve cells is somewhat intriguing because $\alpha 1$-tubulin expression has been shown in mammals to be restricted to neuronal-type cells (Miller et al., 1987; Wang et al., 2000). A first possibility is that the WT promoter is lacking some elements repressing promoter activity in this particular glial cell type. A second more interesting possibility is that, as reported for other proteins (Ankerhold et al., 1998; Bernhardt, 1999; Liu et al., 2002; Schweitzer et al., 2003), $\alpha 1$-tubulin is upregulated in a subset of non-neuronal cells in response to optic nerve lesion.

Our qualitative and quantitative analyses revealed that deletion of sequences between -469 and -406 (EHD mutant) resulted in the complete loss of GFP re-expression in the axotomized RGCs. The observation that GFP expression was totally abolished in two independent EHD lines suggests that the lack of GFP re-expression was not attributable to where the transgene integrated. Furthermore, failure to observe GFP re-expression in the axotomized retina of EHD transgenic fish was not a result of expression levels being below the limits of immunodetection, because a semiquantitative mRNA analysis was also unable to detect any changes in GFP mRNA levels of the retina between control and crush sides. Finally, this lack of regenerative gene induction cannot be attributable to crippling of promoter activity, because GFP expression was induced in lesioned retinas and developing retinal cells, including RGCs, supporting previous observations that gene induction in the axotomized RGCs is not simply a recapitulation of developmental mechanisms (Goldman et al., 2001; Udvadia et al., 2001).

To further determine whether the HD consensus sequence harbored the element or elements necessary for promoter induction after optic nerve crush, we analyzed GFP expression in the HD mutant in which only the HD sequence $(-439$ to -410$)$ had been removed from the WT promoter. Interestingly, HD transgenic promoter was still capable of inducing GFP expression in axotomized RGCs, in a temporal and spatial pattern quite similar to the WT $\alpha 1$-tubulin promoter, but with an overall much weaker intensity. Intriguingly, whereas a statistically significant increase in the intensity of GFP staining was readily observed by quantification of immunofluorescence intensity in the axotomized retinas of both HD2 and HD4 lines, mRNA analysis detected an increase in GFP mRNA levels only in HD2. This apparent discrepancy could be caused by already decreasing levels of GFP mRNA by $7 \mathrm{~d}$ after crush, which are not quantitatively reflected by the levels of immunofluorescence for GFP, a stable protein. Consistent with this idea is the observation that the fold increases obtained from the quantitative RT-PCR analysis were consistently lower than those measured with immunofluorescence. We also cannot rule out an upregulation of GFP mRNA levels in retinal cells other than RGCs, whose increase was undetectable by immunodetection. The observation that only a subset of RGCs in the axotomized HD retinas was able to re-express high levels of GFP is somewhat interesting. As other vertebrates, zebrafish RGCs are classified into various subtypes based on morphological criteria (Mangrum et al., 2002). If cells that re-express high levels of GFP in the lesioned HD retinas correspond to a specific subtype of RGC, it might indicate that regulation of $\alpha 1$ tubulin promoter activity within different types of RGCs is controlled by different regulatory elements. Taken together, these deletion studies suggest that the promoter region between -469 and -406 bp contains at least two distinct and independent elements required for $\alpha 1$-tubulin promoter activity in the RGCs after optic nerve crush: one element located between -469 to -440 for initiation of activity and another element containing the HD sequence located between -439 to -410 bp for regulating activity levels. It is interesting that this latter sequence is also found in the rat promoter, although in the opposite DNA strand. Whether this orientation of the rat HD sequence would function similarly in the fish is not known. Other elements located outside of the 64 bp sequence analyzed here are also likely to be of importance in the regulation of $\alpha 1$-tubulin promoter activity because deletion of an upstream 200 bp sequence (between - 1086 and -846 ) also resulted in the heterogeneous expression of GFP in the axotomized RGCs (Goldman and Ding, 2000).

We then investigated whether the elements required for $\alpha 1$ tubulin expression in axotomized RGCs were also required for promoter re-induction in other regeneration models of the zebrafish visual system. After eye injury, the fish retina is capable of regenerating through induction of neurogenesis (Otteson and Hitchcock, 2003). In our model of retinal puncture, we observed DAPI-positive pyknotic nuclei indicative of cell death and a significant number of BrdU-positive nuclei signifying cell proliferation. We show here that retinal puncture in the WT transgenic fish activated the $\alpha 1$-tubulin promoter, as indicated by robust 
GFP expression at the lesion site as early as $3 \mathrm{~d}$ after injury. Interestingly, eye puncture was also able to elicit GFP expression in the lesioned retinas of both EHD and HD fish. This result corroborates the previous observations that a -302 bp upstream fragment of the $\alpha 1$-tubulin promoter was still capable of inducing GFP immunoreactivity in dissected cultured retinal explants (Hieber et al., 1998). The observation that the EHD promoter was capable of inducing GFP expression in the retinal cells after eye injury but not optic nerve crush, suggests that the elements necessary for activating $\alpha 1$-tubulin promoter in the lesioned retina are different from those required in the axotomized retina. After retinal puncture, at least three different categories of GFPpositive cells could be distinguished by double-immunostaining. The first type, located in the INL and the ONL, consisted of Müller glia-type cells. The observation of GFP expression in glial cells was somewhat unexpected because $\alpha 1$-tubulin expression has been generally thought to be restricted to neuronal-type cells (Miller et al., 1987; Wang et al., 1998). It is however of great interest in the light of a previous study showing that after NMDAinduced retinal damage in the young chicken, Müller glial cells were able to re-enter the cell cycle and re-express transcription factors expressed by embryonic retinal progenitors (Fischer and Reh, 2001). Proliferation of Müller glial cells and their subsequent migration to the ONL has also been reported in the goldfish in response to laser-induced lesions of the retina (Braisted et al., 1994). Whether Müller glia might also be a source for neural progenitor cells in response to retinal lesion in the zebrafish remains to be established, and our lesion model provides us with a useful tool to further examine this issue. The second type of GFPpositive cells corresponded to cells that were, or had been, proliferating as indicated by their staining for BrdU, and that are likely to be progenitor retinal cells. The third cell type corresponded to a few HuC/D-positive neurons, which expressed GFP, possibly in response to the lesion-induced axotomy of their processes. Finally, a number of GFP-positive cells did not co-stain for any of the markers used and might correspond to cells at different differentiation stages or resident microglial cells (Herbomel et al., 2001).

In conclusion, we have identified a small region $(-469$ to $-406)$ of the $\alpha 1$-tubulin promoter that contains elements playing a pivotal role in re-inducing and regulating gene expression in the RGCs after optic nerve crush. We identified one of these elements as a repetitive HD sequence; however, other sequences within this DNA region appear to collaborate with the HD sequence, the most likely candidate being the E-box sequence residing just upstream. The identification of these elements is the first step in a series of studies aimed at identifying mechanisms underlying successful optic nerve regeneration. The DNA sequence of these elements suggests they bind to (Pit-Oct-Unc)related HD and helix-loop-helix E-box binding proteins. Elucidating the particular proteins that are specifically involved in regulating $\alpha 1$-tubulin promoter activity during optic nerve regeneration in the zebrafish will be the focus of our future studies.

\section{References}

Ankerhold R, Leppert CA, Bastmeyer M, Stuermer CA (1998) E587 antigen is upregulated by goldfish oligodendrocytes after optic nerve lesion and supports retinal axon regeneration. Glia 23:257-270.

Baas PW (1997) Microtubules and axonal growth. Curr Opin Cell Biol 9:29-36.

Bamji SX, Miller FD (1996) Comparison of the expression of a T alpha 1:nlacZ transgene and $\mathrm{T}$ alphal alpha-tubulin mRNA in the mature central nervous system. J Comp Neurol 374:52-69.

Barthel LK, Raymond PA (1990) Improved method for obtaining 3-microns cryosections for immunocytochemistry. J Histochem Cytochem 38:1383-1388.

Bernhardt RR (1999) Cellular and molecular bases of axonal regeneration in the fish central nervous system. Exp Neurol 157:223-240.

Bormann P, Zumsteg VM, Roth LWA, Reinhard E (1998) Target contact regulates GAP-43 and $\alpha$-tubulin mRNA levels in regenerating retinal ganglion cells. J Neurosci Res 52:405-419.

Braisted JE, Essman TF, Raymond PA (1994) Selective regeneration of photoreceptors in goldfish retina. Development 120:2409-2419.

Burrell HR, Dokas LA, Agranoff BW (1978) RNA metabolism in the goldfish retina during optic nerve regeneration. J Neurochem 31:289-298.

Byrd CA, Brunjes PC (2001) Neurogenesis in the olfactory bulb of adult zebrafish. Neuroscience 105:793-801.

Chitnis AB, Kuwada JY (1990) Axonogenesis in the brain of zebrafish embryos. J Neurosci 10:1892-1905.

Fischer AJ, Reh TA (2001) Müller glia are a potential source of neural regeneration in the postnatal chicken retina. Nat Neurosci 4:247-252.

Fournier AE, McKerracher L (1997) Expression of specific tubulin isotypes increases during regeneration of injured CNS neurons, but not after the application of brain-derived neurotrophic factor (BDNF). J Neurosci 17:4623-4632.

Gloster A, Wu W, Speelman A, Weiss S, Causing C, Pozniak C, Reynolds B, Chang E, Toma JG, Miller FD (1994) The T $\alpha 1 \alpha$-tubulin promoter specifies gene expression as a function of neuronal growth and regeneration in transgenic mice. J Neurosci 14:7319-7330.

Gloster A, El-Bizri H, Bamji SX, Rogers D, Miller FD (1999) Early induction of T $\alpha 1 \alpha$-tubulin transcription in neurons of the developing nervous system. J Comp Neurol 405:45-60.

Goldman D, Ding J (2000) Different regulatory elements are necessary for $\alpha 1$ tubulin induction during CNS development and regeneration. NeuroReport 11:3859-3863.

Goldman D, Hankin M, Li Z, Dai X, Ding J (2001) Transgenic zebrafish for studying nervous system development and regeneration. Transgenic Res 10:21-33.

Gozes I, Littauer UZ (1978) Tubulin microheterogeneity increases with rat brain maturation. Nature 276:411-413.

Herbomel P, Thisse B, Thisse C (2001) Zebrafish early macrophages colonize cephalic mesenchyme and developing brain, retina, and epidermis through a M-CSF receptor-dependent invasive process. Dev Biol 238:274-288.

Hieber V, Agranoff BW, Goldman D (1992) Target-dependent regulation of retinal nicotinic acetylcholine receptor and tubulin RNAs during optic nerve regeneration in goldfish. J Neurochem 58:1009-1015.

Hieber V, Dai X, Foreman M, Goldman D (1998) Induction of $\alpha 1$-tubulin gene expression during development and regeneration of the fish central nervous system. J Neurobiol 37:429-440.

Horner PJ, Gage FH (2000) Regenerating the damaged central nervous system. Nature 407:963-970.

Kimmel CB, Ballard WW, Kimmel SR, Ullmann B, Schilling TF (1995) Stages of embryonic development of the zebrafish. Dev Dyn 203:253-310.

Larison KD, Bremiller R (1990) Early onset of phenotype and cell patterning in the embryonic zebrafish retina. Development 109:567-576.

Lewis SA, Lee MG, Cowan NJ (1985) Five mouse tubulin isotypes and their regulated expression during development. J Cell Biol 101:852-861.

Liu Q, Londraville RL, Azodi E, Babb SG, Chiappini-Williamson C, Marrs JA, Raymond PA (2002) Up-regulation of cadherin-2 and cadherin-4 in regenerating visual structures of adult zebrafish. Exp Neurol 177:396-406.

Lorenzo PI, Menard C, Miller FD, Bernal J (2002) Thyroid hormonedependent regulation of T $\alpha 1 \alpha$-tubulin during brain development. Mol Cell Neurosci 19:333-343.

Ma Y, Campenot RB, Miller FD (1992) Concentration-dependent regulation of neuronal gene expression by nerve growth factor. J Cell Biol 117:135-141.

Malicki J (1999) Development of the retina. In: Methods in cell biology, the zebrafish biology (Detrich HW, Westerfield III M, Zon LI, eds), pp 273299. New York: Academic.

Mangrum WI, Dowling JE, Cohen ED (2002) A morphological classification of ganglion cells in the zebrafish retina. Vis Neurosci 19:767-779.

Mathew TC, Miller FD (1990) Increased expression of T $\alpha 1 \quad \alpha$-tubulin mRNA during collateral and NGF-induced sprouting of sympathetic neurons. Dev Biol 141:84-92.

Mathew TC, Miller FD (1993) Induction of T $\alpha 1 \alpha$-tubulin mRNA during 
neuronal regeneration is a function of the amount of axons lost. Dev Biol 158:467-474.

Menard C, Hein P, Paquin A, Savelson A, Yang XM, Lederfein D, BarnabeHeider F, Mir AA, Sterneck E, Peterson AC, Johnson PF, Vinson C, Miller FD (2002) An essential role for a MEK-C/EBP pathway during growth factor-regulated cortical neurogenesis. Neuron 36:597-610.

Miller FD, Naus CCJ, Durand M, Bloom FE, Milner RJ (1987) Isotypes of $\alpha$-tubulin are differentially regulated during neuronal maturation. J Cell Biol 105:3065-3073.

Miller FD, Tetzlaff W, Bisby MA, Milner RJ (1989) Rapid induction of the major $\alpha$-tubulin mRNA, T $\alpha 1$, during nerve regeneration in adult rats. J Neurosci 9:1452-1463.

Otteson DC, Hitchcock PF (2003) Stem cells in the teleost retina: persistent neurogenesis and injury-induced regeneration. Vision Res 43:927-936.

Perry GW, Burmeister DW, Grafstein B (1987) Fast axonally transported proteins in regenerating goldfish optic axons. J Neurosci 7:792-806.

Plunet W, Kwon BK, Tetzlaff W (2002) Promoting axonal regeneration in the central nervous system by enhancing the cell body response to axotomy. J Neurosci Res 68:1-6.

Roy NS, Wang S, Jiang L, Kang J, Benraiss A, Harrison-Restelli C, Fraser RAR, Couldwell WT, Kawaguchi A, Okano H, Nedergaard M, Goldman SA (2000) In vitro neurogenesis by progenitor cells isolated from the adult human hippocampus. Nat Med 6:271-277.

Schmitt EA, Dowling JE (1999) Early retinal development in the zebrafish, Danio rerio: light and electron microscopic analyses. J Comp Neurol 404:515-536.

Schweitzer J, Becker T, Becker CG, Schachner M (2003) Expression of protein zero is increased in lesioned axon pathways in the central nervous system of adult zebrafish. Glia 41:301-317.

Skene JHP (1989) Axonal growth-associated proteins. Annu Rev Neurosci 12:127-156.

Stanchi F, Corso V, Scannapieco P, Ievolella C, Negrisolo E, Tiso N, Lanfranchi G, Valle G (2000) TUBA8: A new tissue-specific isoform of $\alpha$-tubulin that is highly conserved in human and mouse. Biochem Biophys Res Commun 270:1111-1118.

Suter DM, Forscher P (2000) Substrate-cytoskeletal coupling as a mechanism for the regulation of growth cone motility and guidance. J Neurobiol 44:97-113.

Tetzlaff W, Alexander SW, Miller FD, Bisby MA (1991) Response of facial and rubrospinal neurons to axotomy: changes in mRNA expression for cytoskeletal proteins and GAP-43. J Neurosci 11:2528-2544.

Udvadia AJ, Linney E (2003) Windows into development: historic, current, and future perspectives on transgenic zebrafish. Dev Biol 256:1-17.

Udvadia AJ, Koster RW, Skene JHP (2001) GAP-43 promoter elements in transgenic zebrafish reveals a difference in signals for axon growth during CNS development and regeneration. Development 128:1175-1182.

Villasante A, Wang D, Dobner P, Dolph P, Lewis SA, Cowan NJ (1986) Six mouse alpha-tubulin mRNAs encode five distinct isotypes: testis-specific expression of two sister genes. Mol Cell Biol 6:2409-2419.

Wang S, Wu H, Jiang J, Delohery TM, Isdell F, Goldman SA (1998) Isolation of neuronal precursors by sorting embryonic forebrain transfected with GFP regulated by the $\mathrm{T}$ (alpha) 1 tubulin promoter. Nat Biotechnol 16:196-201.

Wang S, Roy NS, Benraiss A, Goldman SA (2000) Promoter-based isolation and fluorescence-activated sorting of mitotic neuronal progenitor cells from the adult mammalian ependymal/subependymal zone. Dev Neurosci 22:167-176.

Wilson SW, Ross LS, Parrett T, Easter SS (1990) The development of a simple scaffold of axon tracts in the brain of the embryonic zebrafish, Brachydanio rerio. Development 108:121-145.

Wu W, Gloster A, Miller FD (1997) Transcriptional repression of the growth-associated T $\alpha 1 \alpha$-tubulin gene by target contact. J Neurosci Res 48:477-487.

Yazulla S, Studholme KM (2001) Neurochemical anatomy of the zebrafish retina as determined by immunocytochemistry. J Neurocytol 30:551-592. 